\title{
Behavior of Cylindrical Tanks Resting on Port Said Soil
}

Ibrahim elkersh, Ibrahim elarabi, Omar El Gendy

\begin{abstract}
The problem of settlement in Port-Said area had a great concern for many years. This is mainly related to the presence of soft clay layers, which extend in some places to a depth of about $60 \mathrm{~m}$ under the ground surface. Parametric study is carried out to study the behavior of cylindrical tanks under different variables and conditions in Port Said area. For achievement of the task, typical soil stratification and properties of Port-said area are considered. The response of circular tanks is analyzed by a finite element axi-symmetric shell formulation. The analysis accounts for the soil layers defined by the modulus of compressibility or compression index. This enables considering sand or clay layers with their appropriate properties. Full compatibility between the tank wall, tank base and the soil is considered in the analysis. The study presents guidelines and diagrams for cylindrical tanks that may be used in Port-Said area.
\end{abstract}

